\title{
MOVING TOWARD OPEN GEOSPATIAL SYSTEMS: THE UN OPEN GIS INITIATIVE
}

\author{
M. A. Brovelli ${ }^{1,2^{*}}$, K. J. Li ${ }^{3}$, K. S. Eom ${ }^{4}$ \\ 1 Politecnico di Milano, GEOLab, DICA Department - maria.brovelli@polimi.it \\ 2 IREA CNR \\ 3 Pusan National University, Department of Computer Science and Engineering - lik@pnu.edu \\ 4 Geospatial Information Section, United Nations - eom@un.org
}

Commission IV, WG IV/4

KEY WORDS: Openness, Geospatial Technologies, Spatial Data and Information Infrastructures, UN geospatial mandates and operations, hybrid GIS architecture and infrastructure

\begin{abstract}
:
The UN Open GIS Initiative is an ongoing Partnership Initiative leaded by the United Nations Geospatial Operations. The Initiative, established in March 2016, is supported by several UN Member States, UN Field Missions, UN Agencies and technology contributing partners (international organizations, academia, NGOs, and the private sector) and takes full advantage of their expertise.

The target is the creation of an extended spatial data infrastructure that meets the requirements of the UN Secretariat (including UN field missions and regional commissions), and then expands to UN agencies, UN operating partners and developing countries. The paper presents the activities done in the past year and the status of the Initiative.
\end{abstract}

\section{INTRODUCTION}

The UN Open GIS Initiative (Eom et al., 2017; UN Open GIS Initiative, 2019) is an ongoing Partnership Initiative leaded by the United Nations Geospatial Operations. The Initiative, established in March 2016, is supported by several UN Member States, UN Field Missions, UN Agencies and technology contributing partners (international organizations, academia, NGOs, and the private sector) and takes full advantage of their expertise.

The target is the creation of an extended spatial data infrastructure (with the term "extended" it is meant that the whole ancillary applications which are nowadays part of the procedures and activities of the organization are also subjects of the initiative) that meets the requirements of the UN Secretariat (including UN field missions and regional commissions), and then expands to $\mathrm{UN}$ agencies, UN operating partners and developing countries.

Mandates and operations which must be considered in the design and the development of the system includes activities in support to (Fig.1):

- $\quad$ the UN Security Council;

- $\quad$ the Executive Committee \& Deputy Committee (EC/DC) of the UN Secretariat;

- $\quad$ the UN Operations and Crisis Centre (UNOCC);

- $\quad$ the UN Secretariat (all Departments/Offices, Regional Commissions);

- the UN Peace Operations (DPO, DPPA, DOS and UN field missions);

- the UN-GGIM, as Co-Secretariat (with DESA/Statistics Division);
- Member States for technical assistance on international boundaries;

- UN agencies.

$\mathrm{UN}$ requirements related to geospatial information include the building of Situational Awareness Geospatial Platforms, the support of the fulfilment of UN core mandates for what refers to or depends on geospatial information, the saving of lives and the support to emergency operations and the enablement, thanks to geospatial models and methods, of cost-effective operations. Details and some relevant application examples are shown in Table 1.

The choice of openness is in line with the general tendency in the past few decades of the increased adoption of open-source software and open data to design and develop collaborative global solutions (Brovelli et al., 2017) and is corroborated by the vision of professionals in key organizations in the global geospatial community, who suggests that this trend is likely to have an even more profound impact in the future (Coetzee et al., 2020). Moreover, in this specific case, being UN involved in the project, some other relevant aspects must be considered like the increasing in UN operational demands and, consequently, costs; the constraints of monopolistic proprietary solutions; the current limit to support Member States for capacity building and technology transfer.

In the past, it was mentioned often disadvantage such as technical support weakness or software incompleteness relatively in comparison with commercial solutions. However, the quality of open-source products is getting robust and other advantages such as easy to develop/add a new function due to flexibility and scalability of FOSS4G (Free and Open Source for Geospatial Applications), and easy to share/transfer 
technologies between $\mathrm{UN}$ and host nations due to open-license increased the demands in using FOSS4G at UN operations.

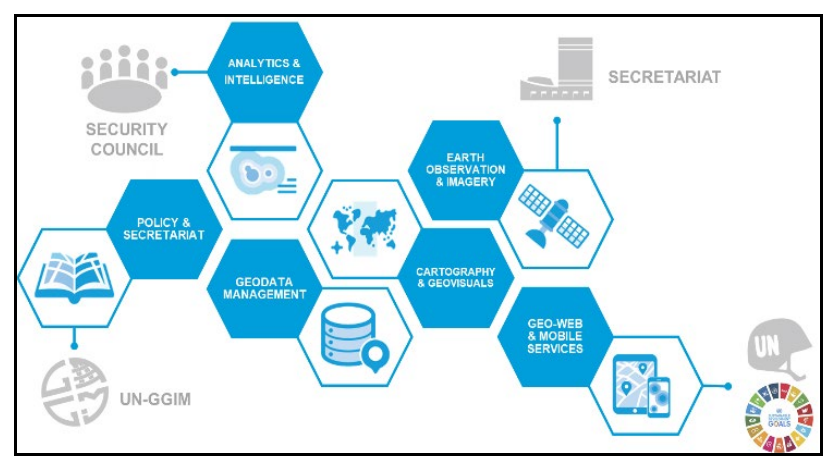

Figure 1. Mandates and operations to be fulfilled by the UN Open GIS Initiative.

The UN Open GIS Initiative more than a final complex product to be transferred, is an ecosystem where the various actors involved contribute to its realization. This aspect makes the journey longer because the solution is built step by step not for the people who will use it, but with the people who is developing it. The community around UN Open GIS is increasing and currently many UN agencies are contributing, each of them with their expertise and bringing their requests, solutions, and original points of view in the system.

\begin{tabular}{|l|l|}
\hline & $\begin{array}{l}\text { Geospatial visualisation for improving } \\
\text { situational awareness }\end{array}$ \\
Geospatial analysis for supporting decision \\
making \\
Smart knowledge-based platform for UN \\
operations
\end{tabular}

Table 1. Main UN requirement related to geospatial information.

The paper describes the various components of the initiative (Working Groups and Pilot Projects) and presents the reached level of maturity. Lessons learned and future developments conclude the paper.

\section{THE STRUCTURE OF THE INITIATIVE}

The initiative presents many complexities and proceeds by working groups and pilot projects, which are coordinated by an executive board (vertical management) and by monthly informative meetings (horizontal management) to which all members participate.

At this stage, there are five active working groups:
WG1. Hybrid GIS Infrastructure
WG2. Capacity Building
WG3. Geo-Analysis
WG4. Geo-Data Collection
WG5. Geo-AI

and some pilot projects: the Pilot Hybrid GIS Infrastructure, the Geo Analysis Practice, the UN Vector Tile Toolkit, the CloudFree Satellite Imagery, the Mobile Open GIS, the UNMISS (United Nations Mission in South Sudan) Story Map, and the OpenDroneMap. Pilot Projects, shortly described under the working group of reference, are often transversal with respect to the working groups, improving the cohesion and collaboration of the Initiative's members.

\section{THE UN OPEN GIS WORKING GROUPS}

\subsection{WG1: Hybrid GIS Infrastructure}

The main element to be implemented is the Spatial Data Infrastructure, which is the backbone of the entire system. This must be developed considering the status of activities at UN, which are based on proprietary solutions. Obviously, the migration to the open source must be gradual and open source will be complementing with the existing proprietary solutions to strengthen the geospatial service capability to effectively fulfill the increasing operational demands, considering as the full scale of Hybrid GIS solutions for the UN Secretariat (including UN field missions and regional commissions) and then expand to UN agencies, UN operating partners and developing countries. The architecture of the system, with all software details, is depicted in Figure 2.

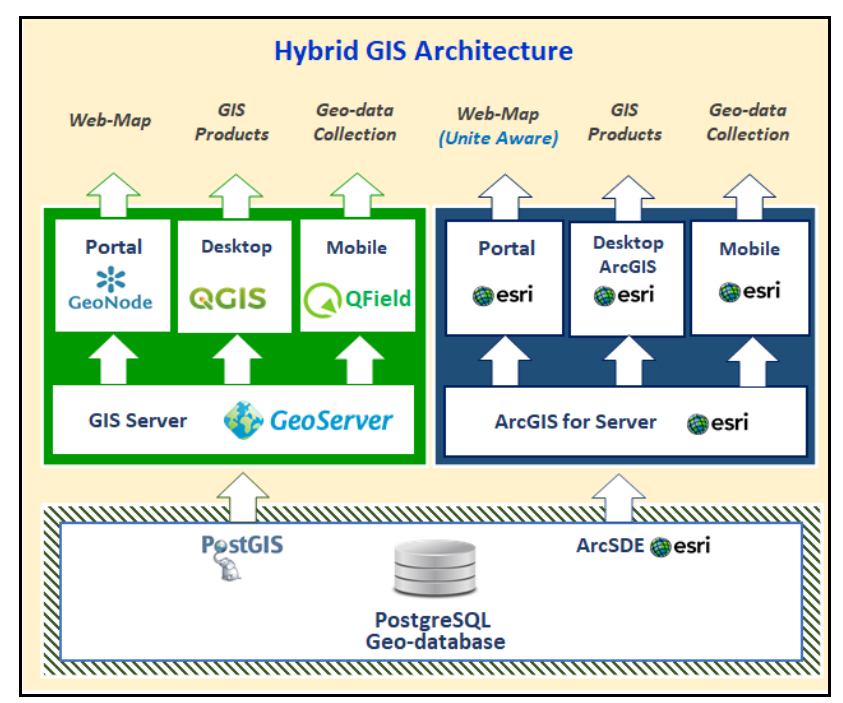

Figure 2. The hybrid GIS Architecture. 
The complete rollout of the Hybrid GIS infrastructure is planned by the middle of March 2022, while one more year will be devoted to the final testing of the system. WG-1 has initiated a Pilot Project in 2020 for proof of concept through design and implementation of a hybrid GIS prototype to support two parts of the whole system: the Unite Maps, with the integration of the open-source and the proprietary databases and the Open GeoPortal, built upon GeoNode (GeoNode Contributors, 2021), a web-based collaborative platform for deploying spatial data infrastructures), and the mapserver GeoServer (Open Source Geospatial Foundation, 2021). As a database the very mature and well know PostgreSQL (The PostgreSQL Global Development Group 2021), with the spatial extension PostGIS (PostGIS 2021), is used.

Main contributors of this development are the Korea Research Institute for Human Settlements (KRIHS), the UN Geospatial Information Section (UNGIS), the UN Global Service Centre (UNGSC), the World Food Programme (WFP), and GeoSolutions.

\subsection{WG2: Capacity Building}

Two main activities have been carried out by the Capacity Building working group. The former refers to training sessions provided to the UN staff members in professional area of GIS but who had only made use of proprietary tools. This process is of fundamental importance for an organization that wants to migrate to the use of new software, in this case to open-source software. The acquisition of new skills is of interest but obviously involves an increase in work, particularly heavy for staff (for example those of peacekeeping missions) who operate in difficult working environment.

Therefore, training materials suitable for the day-to-day working needs and experiences of UN personnel must be designed and developed. The integration of the new software must be seen as an advantage and not as a useless burden of activities.

Training has been conducted through the open-source e-learning platform of Politecnico di Milano, namely: Beep. It is a multiplatform (working with all operative systems and all browsers) and responsive (working on PC, tablet and smartphone) web application. Beep is the Learning Management System (LMS) used by Politecnico di Milano to manage all its courses. The tutors of the training sessions have been volunteers of GeoForAll, the OSGeo Education Committee (OSGeo, 2021). The training courses organized so far have been the "Basic QGIS" and the "PostGIS" and totally have seen the completion of the exam for around $120 \mathrm{UN}$ staff members (the enrolment was higher but, for many reasons, only around the half, in average, of them were able to take and pass the exam).

The latter activity of the Working Group was that of organizing Challenges, sponsored by OSGeo, for developing training material (Franceschi et al, 2019; Ilie et al, 2019; Brovelli et al, 2020; Anbaroğlu et al., 2020). These activities were organised by the OSGeo UN Committee with the guidance of the UN GIS experts. The two activities planned in 2021 refers to the development of training material related to

- $\quad$ pgrRouting (pgRouting Community, 2021), a library that extends PostGIS / PostgreSQL geospatial database to provide geospatial routing functionality;

- advanced satellite imagery analysis, Machine Learning included, with QGIS by means of advanced functionalities and plugins (e.g. : SCP, dzetsaka, GEE Timeseries Explorer, Google Earth Engine Data Catalog, PolSAR tools, ENMAP-Box3, DeepLearning Tools, FORCE4Q, SAGA interface).
The working group is chaired by Politecnico di Milano, and the United Nations Global Service Centre (UNGSC) and is supported by the contribution of GeoForAll members.

\subsection{WG3: Geo-Analysis}

The WG3 aims to develop and deliver open geo-analytic functions for UN operations. The first phase (2016-2019) of the activity consisted in the revision of the procedures and methods implemented at the United Nations Geospatial Operations and their modelling in basic functionalities and their concatenation. The main processes considered are the following.

Situational Awareness: the UN Open GIS System must be able to respond adequately to the requests of the various $\mathrm{UN}$ peacekeeping and political missions and UN agencies, to provide products that allow the analysis of very different critical situations. Exemplary cases, although not exhaustive, are represented by the rapid assessment of the extent and severity of natural and man-made disasters; support for search / rescue and reconstruction operations; confirmation of reported events and critical situations. Due to this multiplicity of interventions, analytical models often require a high degree of customization based both on local geospatial data and multispectral and radar satellite data.

Safety and Security: it is necessary to provide simulation of different threat scenarios for UN Premises in the field, very often based on different type of analysis and modelling tools.

Military Operations and Protection of Civilians: Geospatial Intelligence (GeoINT) products for early detection of threats to support peacekeeping operations (e.g., patrol route planning, evacuation, identification of possible ambush areas, etc.) and Protection of Civilians (e.g., preparedness and management of camps) are fundamental components of the system.

Human Rights Violation Investigation: detection and assessment of the extent and severity of various atrocities and of the locations of possible mass graves in conflict areas.

Epidemiological Analysis: Analyses of the spread, extent, occurrence, and severity of epidemiological crisis, which generally depend on the type of disease. Therefore, various analytical functions and customizable tools are required.

UN Mission Support: Planning of the best suitable locations for UN Camps, Internally Displaced People and Refugee camps. In various UN missions, such as Darfur, Mali and Somalia, assistance in identification of possible reserves of ground water for the peacekeepers and for the local communities has also to be provided.

Environmental Assessment: UN has an obligation to compliance of rules and regulations published by host countries or provided by $\mathrm{UN}$ itself to protect environment of the area where UN serves. Therefore, it is required reductions of the footprint, facility management, water-waste management such as proper collection and disposal of wastewater, biohazard materials, etc. GIS analysis services have to be provided to the Environmental Officers in the missions and to the UN Headquarters which assists them to conduct environmental assessments.

During this first phase of the UN Open GIS Initiative, JAVAbased Geo-Analytic libraries for GeoServer WPS, uDig and GeoTools were developed (UN Open GIS Initiative, 2021). In 
the second phase, from the beginning of 2020, QGIS embedded Geo Analytic functions are under development.

The collaboration with WG 2, brought also to the development of training material related to the advanced functionalities implemented in QGIS and needed to the UN GIS staff for their activities (Amici, 2020).

\subsection{WG4: Geo-Data Collection}

This working group aims to develop open-source software solutions for collecting geospatial data from diverse sources and environments. Since the data collection is the first step for the entire lifecycle of geospatial information and application, it is one of the most challenging parts in the UN Open GIS initiative. Furthermore, the geospatial data infrastructure in many UN field mission areas is not yet well established. It includes building geospatial information infrastructure as well as collecting dynamic geospatial data collected from several types of sensors.

Any possible approaches for collecting geospatial data using open-source software are investigated such as using legacy data sets and collaborating VGI such as OpenStreetMap (OSM) Foundation and from mobile solutions to OpenDroneMap. The scope of this working group covers not only the collecting geospatial data but also processing and controlling quality of collected data sets.

An extensive survey on open-source mobile solutions for handling geospatial data has been done, which is very demanded to collect geospatial field data. QField (OPENGIS.ch, 2021), KoBo Toolbox (Harvard Humanitarian Initiative, 2021), and Geopaparazzi/SMASH (Geopaparazzi, 2021) were assessed in the field by the teams of the two peacekeeping missions UNMISS and MONUSCO (Mission de l'Organisation des Nations Unies pour la stabilisation en République démocratique du Congo).

The tests were meant to evaluate the effectiveness of these open-source mobile solutions in UN field operational environment, to setup the fundamental process for integration, implementation, and use of GIS mobile application under UN Open GIS Architecture and the main packages on which its implementation is based.

Besides that, UNMISS is also working on the development of an open-source platform to provide a Story Map to geolocate and geotag public information stories, articles and narratives of UNMISS's quick impact projects. The Story Map, whose architecture is shown in Figure 3) will utilize open-source solutions and the Microsoft Azure cloud environment available for the United Nations.

The UN Vector-Tile Toolkit (UNVT) project led by the Geospatial Authority of Japan (GSI) has been developing and deploying a vector-tile solution at UNGSC for optimal dissemination of vector data through thin UN communication bandwidth (Fujimura et al, 2019; The United Nations Vector Tile Toolkit, 2021)

And a quality control module on vector data has also been developed for geospatial data as a QGIS plug-in by a Korean team (ODTBuilder, 2021). The plugin can be used for inspecting and validating geospatial data with user-defined conditions such as non-overlapping, feature duplication, contour line intersection, disconnected lines, etc.

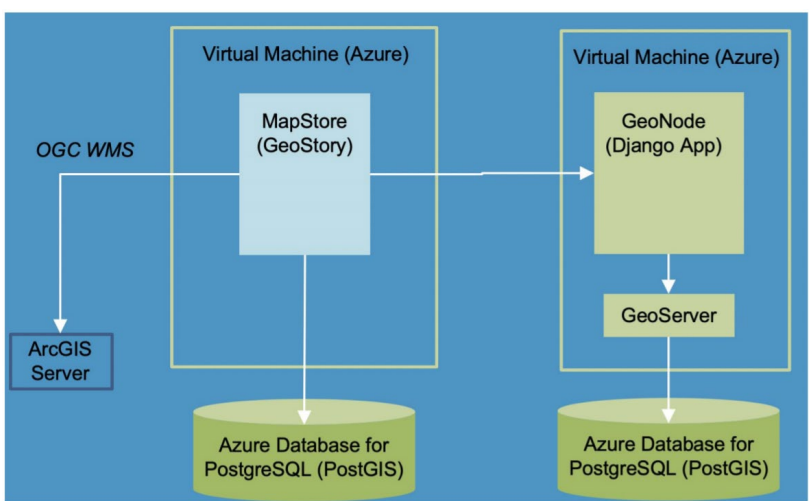

Figure 3. UN MISS Story Map architecture

Another QGIS plugin, developed by the Politecnico di Milano team allows the spatial accuracy and completeness assessment of the OSM building layer with respect to authoritative datasets (Brovelli and Zamboni, 2018; Opengeolab, 2021).

Recently an expert group has been established in this working group to provide a drone-base solution for collecting imagery data with the support from OpenDroneMap (ODM) project team (OpenDroneMap Contributors, 2021). Drone is a handy and efficient method to acquire live geospatial imagery data. Several solutions from ODM project are ready to deploy in real applications of UN field missions and share geo-rectified imagery data via web-environment. Since the capacity building is a key part of successful deployment and utilization of ODM solutions, we invest a large amount of effort for training the UN GIS officers through training workshops and meetings.

The collaboration with OSM Foundation and HOT (Humanitarian OpenStreetMap Team) is also a key activity in this working group as it is the best digital map covering the entire earth in terms of the quality and sustainability. This collaboration mainly led by the GIS team of UNGSC includes not merely the utilization of OSM as a part of the UN base maps but also contribution from UN to OSM.

The geospatial data collection also covers indoor spaces as the UN premises such as UN camps and refugee camps, and complex building structures like the UN Headquarters building in New York City over the world. Tools for collecting indoor maps in OGC IndoorGML format as an international standard for $2 \mathrm{D}$ and $3 \mathrm{D}$ have been developed by the Pusan National University team as open-source software (STEMLab, 2021).

\subsection{WG5: Geo-AI}

Geo-AI is the latest working group born under the umbrella of the UN Open GIS initiative. Its birth was motivated by the growth in demand for analytical geospatial information products in the decision-making processes of the UN Secretariat and various UN agencies. The main objective of the Working Group is to leverage AI applications in geospatial work, with a particular emphasis on using artificial intelligence to interpret and analyze satellite imagery.

The Working Group is chaired by UN Global Pulse, Food and Agriculture Organization (FAO) and Politecnico di Milano; researchers and industry leaders are collaborating to research, elaborate and adopt innovations, best practices, and recommendations that can support geospatial analysis. 
The first initiative was an open consultation (Logar, 2020) to consolidate the expertise of its growing members. The aims of this event were to share the activities and aspirations in the field of Geo-AI of both UN Agencies and external actors and to gather feedback and determine potential collaborations among the various stakeholders present on priorities in the Geo-AI space to promote and further support UN-system operational response.

On the side of UN, the International Telecommunication Union introduced the AI For Good Global Summit, organized by ITU with XPRIZE Foundation in partnership with over 35 sister United Nations agencies, Switzerland and ACM and with the goal of identifying practical applications of AI and scale them for global impact. The summit, due to Covid, was changed from an annual event to a continuous digital one and some common initiatives were planned. Among them, an introductory Handson on Satellite data analysis and Machine Learning classification with QGIS and a Workshop on the links between Digital Earth and GeoAI. After that, the UN Office on Drugs and Crime (UNODC) presented their work using satellite imagery to identify and monitor the farming of illicit crops, United Nations International Children's Emergency Fund (UNICEF) discussed a case of Geo-AI school mapping and FAO their experience in different fields like land cover and crop classification using satellite imagery, phenology and ground reference data, palm tree mapping, fleet estimation, aquaculture mapping, fall armyworm / locust infestation, damage analysis, etc.

An interesting application based on AI and aiming at mosaicking Sentinel 2 and high-resolution satellite data (WorldView, QuickBird, etc.) to obtain free cloud images was presented. It is being under development with the support of the Finnish Government and will be tested by the United Nations Interim Security Force for Abyei (UNISFA) peacekeeping mission. This application, again, is developed with open source and the data are managed by the OpenDataCube (Open Data Cube 2020).

A final panel including representatives of World Geospatial Industry Council, UN Committee of Experts on Global Geospatial Information Management (UN-GGIM) Geospatial Society, Radiant Earth Foundation, UN-GGIM Academic Network, the Humanitarian OpenStreetMap Team and OSGeo highlighted how the development and use of Artificial Intelligence present new ethical challenges that need to be pursued going toward openness guaranteeing and facilitating the full reproducibility.

\section{CONCLUSIONS}

The Initiative represents a relevant example of migration from a proprietary toward an open-source and open data complex system, which necessarily is based on several steps with hybrid progressions. A relevant aspect of the Initiative is that of awarding the community aspect, with the practice of sharing and participation, and the attention given not only to the software products and data but also to the people behind them. United Nations Peacekeeping missions' staff, for instance, who is one of the main recipients of the system, has been highly involved in all the phases of the project, from the design to the assessment and testing of the completed solutions. More than a hardware and software new solution, UN Open GIS is an open ecosystem comprising tools and, above all, communities of users and developers to effectively and efficiently utilize geospatial technology for a better world.

\section{ACKNOWLEDGEMENTS}

The authors want to acknowledge all members contributing to the Initiative

(http://www.unopengis.org/unopengis/about/about05.php).

\section{REFERENCES}

Albertella, A., Brovelli, M. A., Gonzalez Ferreiro, D., 2017, UN Open GIS Capacity Building, Int. Arch. Photogramm. Remote Sens. Spatial Inf. Sci., XLII-4/W2, 11-17, https://doi.org/10.5194/isprs-archives-XLII-4-W2-11-2017.

Amici, L., 2020. QGIS 3.10 - Geo-analysis Practice, https://qgis3-10-geoanalysis-un.readthedocs.io/en/latest/ (10 April 2021).

Anbaroğlu, B., Coşkun, İ. B., Brovelli, M. A., Obukhov, T., and Coetzee, S., 2020, Educational material development on mobile spatial data collection using open-source geospatial technologies, Int. Arch. Photogramm. Remote Sens. Spatial Inf. Sci., XLIII-B4-2020, 221-227, https://doi.org/10.5194/isprsarchives-XLIII-B4-2020-221-2020.

Brovelli, M. A., Minghini, M., Moreno-Sanchez, R., Oliveira, R., 2017, Free and open-source software for geospatial applications (FOSS4G) to support Future Earth, International Journal of Digital Earth, 10 (4), pp. 386-404. doi: 10.1080/17538947.2016.1196505.

Brovelli, M.A.; Zamboni, G., 2018, A New Method for the Assessment of Spatial Accuracy and Completeness of OpenStreetMap Building Footprints. ISPRS Int. J. Geo-Inf. 2018, 7, 289. https://doi.org/10.3390/ijgi7080289.

Brovelli, M. A., Codrina, M. I., Coetzee, S., 2020, Openness and Community Geospatial Science for Monitoring SDGs - An Example from Tanzania, in Sustainable development goals connectivity dilemma: land and geospatial information for urban and rural resilience (Rajabifard A. ed.), CRC PRESSTAYLOR \& FRANCIS GROUP, pp. 313-324.

Coetzee, S.; Ivánová, I.; Mitasova, H.; Brovelli, M.A., 2020, Open Geospatial Software and Data: A Review of the Current State and A Perspective into the Future. ISPRS Int. J. Geo-Inf. 2020, 9, 90. https://doi.org/10.3390/ijgi9020090

Eom, K.S., Arias, R., Brovelli, M.A., Criloux, G., Kang, H.K., Li, K.J., 2017, United Nations Open GIS initiative: the first year of activities, Geoingegneria Ambientale e Mineraria, 2017, 151(2), 5-8, ISSN: 11219041.

Franceschi, S., Adoch, K., Kang, H. K., Hupy, C., Coetzee, S., and Brovelli, M. A., 2019, OSGEO UN Commitee Educational Challenge: a use case of sharing software ad experience from all over the world, Int. Arch. Photogramm. Remote Sens. Spatial Inf. Sci., XLII-4/W14, 49-55, https://doi.org/10.5194/isprsarchives-XLII-4-W14-49-2019. 
Fujimura, H., Martin Sanchez, O., Gonzalez Ferreiro, D., Kayama, Y., Hayashi, H., Iwasaki, N., Mugambi, F., Obukhov, T., Motojima, Y., and Sato, T., 2019, Design and development of the UN Vector Tile Toolkit, Int. Arch. Photogramm. Remote Sens. Spatial Inf. Sci., XLII-4/W14, 57-62, https://doi.org/10.5194/isprs-archives-XLII-4-W14-57-2019.

GeoNode Contributors, 2021. Open-Source Geospatial Content Management System. https://geonode.org/ (10 April 2021).

Geopaparazzi, 2021. Geopaparazzi, SMASH and Survey Server. https://www.geopaparazzi.org/\#/ (10 April 2021).

Harvard Humanitarian Initiative, 2021. KoBoToolbox. https://www.kobotoolbox.org/ (10 April 2021).

Ilie, C. M., Brovelli, M. A., and Coetzee, S., 2019, Monitoring SDG 9 with global open data and open software - a case study from rural Tanzania, Int. Arch. Photogramm. Remote Sens. Spatial Inf. Sci., XLII-2/W13, 1551-1558, https://doi.org/10.5194/isprs-archives-XLII-2-W13-1551-2019.

Ishwar, S., Logar, T., When AI meets GIS: UN Global Pulse and FAO co-chair UN Geo-AI Working Group, 2020. https://www.unglobalpulse.org/2020/12/when-ai-meets-gis-unglobal-pulse-and-fao-co-chair-un-geo-ai-working-group/ (10 April 2021).

Logar, T., UN Open GIS: Working Group 5 - GeoAI First Consultation Call Report, UNOpenGIS-WG5-20201027, 2020. https://www.unglobalpulse.org/wpcontent/uploads/2020/11/UNOpenGIS_WG5_report_final.pdf (10 April 2021).

Open Data Cube, 2020. An Open Source Geospatial Data Management \& Analysis Platform, https://www.opendatacube.org/ ((10 April 2021).

opengeolab, 2021. OSM SAA https://github.com/opengeolab/OSM_SAA (10 April 2021).

Open Geospatial Foundation, 2021. GeoServer http://geoserver.org/ (10 April 2021).

OPENGIS.ch, 2021. QField, https://qfield.org/ (10 April 2021).

OSGeo, 2021 , GeoForAll https://www.osgeo.org/initiatives/geo-for-all/ (10 April 2021).

ODTBuilder, 2021. OpenGDS-Desktop-Qgis Plugin https://github.com/ODTBuilder/OpenGDS-Desktop-QgisPlugin (10 April 2021).

OpendroneMap Contributors, 2021. OpendroneMap. https://www.opendronemap.org/ (10 April 2021).

PostGIS, 2021. Spatial and Geographic objects for PostgreSQL. https://postgis.net/ (10 April 2021).

pgRouting Community, 2021. pgRouting. https://pgrouting.org/ (10 April 2021).

STEMLab, 2021. Tools for IndoorGML. https://github.com/STEMLab/ (10 April 2021).

The PostgreSQL Global Development Group, 2021. PostgreSQL: The World's Most Advanced Open Source
Relational Database. https://www.postgresql.org/ (10 April 2021).

The United Nations Vector Tile Toolkit, 2021. https://github.com/un-vector-tile-toolkit (10 April 2021).

UN Open GIS Initiative, 2021a, UN Open GIS Initiative. http://www.unopengis.org/ (10 April 2021).

UN Open GIS Initiative, 2021b, SW Downloads. $\mathrm{http}$ //unopengis.org/unopengis/resources/resources01.php?id=r esources $01 \&$ notice_id $=\& \mathrm{~s}=\&$ tot $=\&$ search $=\&$ search_cond $=\&$ no $=1 \&$ print_no $=1 \&$ exec $=$ view $\&$ npop $=\&$ sort $=\& d e s c=\&$ search_cat no $=(10$ April 2021). 